\title{
Assessment of Premarital Sexual Practices and Determinant Factors Among High School Students in West Shoa Zone, Oromia Regional State, Ethiopia
}

\author{
Getabalew Endazenaw, Mitsiwat Abebe \\ Ambo University, College of medicine and health sciences, department of nursing, Ambo, Ethiopia
}

Email address:

eyobgetabalew@gmail.com (G. Endazenaw), mitseabe@gmail.com (M. Abebe)

To cite this article:

Getabalew Endazenaw, Mitsiwat Abebe. Assessment of Premarital Sexual Practices and Determinant Factors Among High School Students in West Shoa Zone, Oromia Regional State, Ethiopia. Science Journal of Public Health. Vol. 3, No. 2, 2015, pp. 229-236.

doi: $10.11648 /$ j.sjph.20150302.21

\begin{abstract}
Background: Adolescents face fears, concerns and lack of understanding about their needs, thus asking for or seeking guidance and service is very difficult. Most of youth lack basic knowledge of reproductive anatomy, physiology, how pregnancy or STI/HIV occurs, how to prevent them or where to obtain information and services. Most adults fear that informing young adolescents about sex and teaching them how to protect them was make them sexually active. Objective: the objective of the study was to assess premarital sexual behavior and determinant factors among high school students in west shoa zone. Methodology: the study was conducted in West Shoa Zone Oromia Regional state by using cross sectional study design with structured self-administered questionnaire which supplemented by 3 focus group discussion. The collected data entered and analyzed by using EPinfo and SPSS software. Result: From a total of 843 students who were selected for the study, 828 were participated. One hundred thirty eight $(16.7 \%)$ of the respondents were reported chat chewing, 552(66.7\%) of the respondents were reported alcohol consumption and 322(38.9\%) of the students were attended video. The majority of the respondents, 552 (66.7\%) had ever sexual partner. Among those who had sexual partner, 506 of the students had ever sexual practice. Of the respondents who had sexual practice, 186(36.8\%), 230(45.4\%) of the respondents were less than 15 years and between 15 and 19 years of age at their first sexual exposure respectively. Among the socio-demographic variables, sex of the respondents (female), the respondent's parent educational status and participants who have no pocket money as well as from the behavioral variables, students who did not talk with parent about sexual issues, students who drinking alcohol, participants who attending video/ movies, students who have no information about sexual issues were significantly associated with premarital sexual practice of the students. Conclusion and recommendation-In this study the premarital sexual practice and associated factors were assessed. Based on the finding of both qualitative and quantitative studies premarital and early sexual practice was commonly practiced by most school adolescents. Open discussion about sexual related issues and provide adequate and updated reproductive health related information through school health education, establishing reproductive health club in the school should be promoted.
\end{abstract}

Keywords: Premarital, Sexual, Practice, Determinant, Factors, Students

\section{Introduction}

Sexuality is a universal phenomenon in all-young people. Psychologically adolescents become sexually active at earlier age due to peer pressure, avoidance, indifference and resistance to behavioral change through various forms of denial and rationalism (1).

Abstinence from sex before marriage and delay of sexual debut are important strategies that help to reduce the spread of HIV/AIDS among youth (2). An ever-increasing adolescent sexuality has become one of the majority risk factors in the current pandemic of AIDS and economical and health consequences (1). Traditional practices and poor living conditions often lead young people to engage in sex at an early age (3).

Because of cultural taboos adolescents in many developing countries rarely discuss sexual matters explicitly with their parents. Most information for their patchy knowledge often 
comes from the same sex peers who may themselves lack or incorrectly informed (2).

In Ethiopia Bisrat's study revealed that among the senior high school students in Harar $65 \%$ of males and $20 \%$ of females were sexually active. Another study revealed that $52.8 \%$ of high school students in North Western Ethiopia to be sexually active (have sexual experience) with mean age at first sexual contact being 16 years of age (1).

The sexual behavior and reproductive health of young people in developing countries have attended considerable attention over the last 15 years, youth constitute a large proportion of the population in these countries and are disproportionately affected by HIV/AIDS and others negative reproductive health outcome. The existing literatures document that adolescents engage in premarital sex with insufficient knowledge of reproductive health and family planning, and the small proportion use contraceptive, especially condom (4).

Early initiation of sex poses health risks for both young women and men. Most young adults who enter into a sexual relationship for the first time do not use any form of contraception leaving them vulnerable to unintended pregnancies and unplanned parenthood. Unprotected sex also exposes the young to sexually transmitted infections (3).

Although rates of adolescent child bearing are declining in most countries, more than 13 million adolescent girls give birth at each year in the developing world, and many those births are unplanned. Most sexually active young people don't use contraception, and even those who do, experience higher contraception failure and are more likely to discontinue use than older people. While condoms are key contraception methods for youth many young people view condoms uncomfortable and are often consider as symbol of distrust and are thought to reduce intimacy and sexual pleasure. Study done in three Ghanaian towns revealed that among 704 never married youth age 12-24 years, more than half of the respondents had ever had sexual intercourse (52\%), with adjusted odds for female being 1.6 times higher than males. Nearly all respondents (99\%) know use of condoms, but fewer than half (48\%) could identify any four elements of correct use; females and sexually in experienced youth were the least informed (5)

Study conducted in Gondor revealed 58 percent of students from Gondor Medical School, 55 percent 18 and 19 years-old youths from Harar, and 32 percent of unmarried youth in Jimma were reported to be sexually active (3).

A cross sectional study survey carried out in Ziway high school and parents on sexual matters indicates $54 \%$ of the students felt that it is culturally shameful to discuss about physical and psychological changes during adolescents (10). Another study in Butajira showed that only 5.6\% and 2.6\% of students reported talking about sexuality with friends and family members respectively.(11)

A cross sectional survey conducted in Nekemte indicated $145(21.5 \%)$ of the students had premarital sexual practice with the mean age at fist intercourse 16.2 years and 95 $(65.5 \%)$ had one sexual partner whereas $50(34.5 \%)$ of the students had two or more sexual partners. Among these $102(70.3 \%)$ were males and the remaining were female (12).

According to the study result of sexual experiences and their correlated among Jimma University students thirty five percent of male and $23.1 \%$ female students had sexual intercourse; mean age at first coitus was 18.1 years with an age range of 10-24 years. Furthermore, $88.5 \%$ of them do not have regular sexual partners but only $47.6 \%$ use condom consistently (6).

In Debremarikos town preparatory school $37.7 \%$ of the students were engaged in premarital sex and majority $(66.9 \%)$ of them started at 17 years or more (13). Another study done in Yabelo, 289(71.9\%) of the participants were practiced premarital sexual practice, of which 204(70.5\%) were started premarital sexual activity between the age of 15 and 17 years. In similar study being male, chewing chat, drinking alcohol, watching pornography film were factors statistically associated with premarital sexual practice (14).

Consequences of adolescent sexuality leading to unwanted pregnancy are considerable in involving social, psychological and medical implications that affects the mother the father and the newborn. The problems that encounter the adolescents are multidimensional including fear of guilt, the absence of her menstrual period, possible deterioration of family relation, abandonment of school, hasty and unpromising marriage, health, legal and cultural problems and lesser employment opportunity (1).

Adolescents face fears, concerns and lack of understanding about their needs, thus asking for or seeking guidance and service is very difficult. Moreover, they tend to avoid seeking needed care services. As a result, most of youth lack basic knowledge of reproductive anatomy, physiology, how pregnancy or STI/HIV occurs, how to prevent them or where to obtain information and services. Most adults fear that informing young adolescents about sex and teaching them how to protect them was make them sexually active (7).

Studies from China, Kenya and Nigeria suggest that, lack of communication and negotiation skills, limited parental and community support, inaccessible and unfriendly health services hinder young people's ability to engage in safe sex and wanted sexual relations (8).

A study conducted in Addis Ababa showed that the reasons given by these students for starting sex were peer pressure $(35.2 \%)$, forced sex $(21.6 \%)$, alcohol use $(11.5 \%)$ and drug $(10.3 \%)(9)$.

From these previous studies, it can be understood that premarital sex and unprotected sexual practices are common among school and university adolescents increasing their vulnerability to STIs and HIV infections. Similarly, many students in high school students in west shoa zone may be sexually active and engaged in unsafe sexual practice.

\section{Objectives}

\subsection{General Objective}

- To assess premarital sexual behavior and determinant 
factors among high school students in west shoa zone

\subsection{Specific Objectives}

- To determine the magnitude of premarital sexual behavior among high school students

- To explore the determinant factors of premarital sexual behavior among high school students

\section{Methodology}

\subsection{Study Area and Period}

This study was conducted in west shoa zone high school students in Oromia regional state from April 13 to May 21, 2013 by using structured self-administered questionnaire and focus group discussion. West shoa zone is one of 13 zones in the Oromia regional state. The administrative center for West shoa zone is Ambo which located $112 \mathrm{KmsWest}$ of the capital Addis Ababa. The zone has an estimated total population of $2,315,782$. The zone has 18 Woreda and 22 high schools.

Study design- Cross-sectional survey for quantitative study design was supplemented with focus group discussion

Source and Study population- Source population was all students enrolled in 2012/2013 academic year in high school and the study population was all sampled students in the selected schools.

Inclusion criteria - All students age above 15 years were included.

\subsection{Sampling and Sample Size Determination}

\subsubsection{Sampling Procedure}

A multi-stage sampling technique was implemented. First six high schools were selected randomly. Secondly each high school was stratified into grade. Then proportional sample size was calculated for each grade and simple random sampling technique was used to select the participants after preparing sampling fame.

\subsubsection{Sample Size Determination}

Minimum sample size was determined by using single population proportion sample size calculation formula with the assumption of $52.8 \%$ of high school students in North Western Ethiopia youth premarital sex, a 95\% confidence level $(\mathrm{Za} / 2)$, a $5 \%$ margin of error (d) and Considering the multistage nature of the sampling a design effect of 2 used to multiply the sample size obtained using the above formula. And add 10\% non-response rate. The total sample size was 843 students

\subsubsection{Study Variables}

- Dependent variable- Premarital sexual behavior

- Independent variable

- Socio demographic (Age, Sex, Ethnicity, Literacy status, marital status, Religion, education)

- Parent's job status

- Communication with parents \& peers about sexuality and contraceptive

\subsection{Data Collection}

Data was collected through self-administered questionnaires. The process was assisted by six data collectors, and three supervisors. Both the data collectors and supervisors were trained for 1 day on the objective and methodology of the research, data collection and data recording. The question was open ended and closed. Since the research was supported by qualitative method, a field note was taken.

\subsection{Data Quality Management}

The quality of data was ensured through proper training of data collectors and pre testing of the questionnaire and the result of the pretest was discussed \& some corrections and changes were made if necessary. As well close supervision of data collectors. All collected data was checked for completeness, accuracy and consistency by the principal investigator every day. And anything which was unclear was corrected and communicated to the data collectors on the next day.

\subsection{Data Processing and Analysis}

First the data was checked for completeness and consistency. Then it was coded and entered in the computer using EPI6 software. Then, data was exported to SPSS program for analysis; descriptive summary using frequencies, proportions, graphs were used to present study results. Pvalue less than 0.05 was consider as statistically significant. Bivariate and multivariate logistic regression analyses was conducted to identify determinant factors.

\subsection{Ethical Consideration}

Ethical clearance was obtained from Ambo University RKT office and college of medicine and Health science. Verbal consent was obtained from each selected participant to confirm willingness. Honest explanation of the survey purpose, description of the benefits and an offer to answer all inquiries were made to the respondents. Also affirmation that they are free to withdraw consent and to discontinue participation without any form of prejudice was made. Privacy and confidentiality of collected information was ensured throughout the process.

\subsection{Operational Definitions}

- Premarital sex: A penetrative vaginal sexual intercourse performed before formal marriage.

- Unprotected/ Unsafe sex: A penetrative vaginal sexual intercourse carried out without using condom.

- Sexually active: A student who had had a penetrative sexual intercourse (vaginal) at least once prior to the study.

- Early sexual intercourse: A penetrative sexual intercourse performed before the age of sexual maturity (15 years of age).

- Age of sexual debut: The age at which the first sexual 
commencement occurred.

- Casual sex: A sexual intercourse happening by chance without care or thought.

- Commercial sex partner: A partner who was paid money in exchange for sex.

\section{Result}

\subsection{Socio-Demographic Characteristics of the Study Subjects}

From a total of 843 students who were selected for the study, 828 were participated in the study while 15 were refused to participate in the study, yielding the response rate of $98.2 \%$. Five hundred six $(61.1 \%)$ of respondents were males and $322(38.9 \%)$ were females. The majority of the participants were from grade $9(44.2 \%)$ and grade $10(30 \%)$, participants from grade 11 and 12 constitute $15.2 \%$ and $10.6 \%$, respectively. More than three fourth of the respondents $(88.9 \%)$ were found less than or equal to the age of 19 years.

Three hundred twenty two of the respondents (38.9\%) were followers of the orthodox Christianity, 322 (38.9\%) were Protestants, and the remaining were followers of other religion. The predominant ethnic group is Oromo $690(83.3 \%)$ followed by Amhara 92(11.1\%).

Majority of the respondents $782(94.4 \%)$ were never married (single). [Table 1]

Table 1. Socio demographic characteristics of respondents among west Shoa zone, Oromia region high School students, May, 2013.

\begin{tabular}{|c|c|c|}
\hline Variable & Number & Percent \\
\hline \multicolumn{3}{|l|}{ Sex } \\
\hline Male & 506 & 61.1 \\
\hline Female & 322 & 38.9 \\
\hline \multicolumn{3}{|l|}{ Age } \\
\hline$\leq 19$ & 736 & 88.9 \\
\hline$\geq 20$ & 92 & 11.1 \\
\hline \multicolumn{3}{|l|}{ Religion } \\
\hline Orthodox & 322 & 38.9 \\
\hline Protestant & 322 & 38.9 \\
\hline others & 184 & 22.2 \\
\hline \multicolumn{3}{|l|}{ Ethnicity } \\
\hline Oromo & 690 & 83.3 \\
\hline Amhara & 92 & 11.1 \\
\hline Others & 46 & 5.6 \\
\hline \multicolumn{3}{|c|}{ Marital Status } \\
\hline Single & 782 & 94.4 \\
\hline Married & 46 & 5.6 \\
\hline \multicolumn{3}{|l|}{ Education } \\
\hline Grade 9 & 366 & 44.2 \\
\hline Grade 10 & 248 & 30.0 \\
\hline Grade 11 & 126 & 15.2 \\
\hline Grade 12 & 88 & 10.6 \\
\hline
\end{tabular}

Three hundred twenty two $(38.9 \%)$ of the respondents had illiterate parent, $138(38.916 .7 \%)$ of the respondent's parents were able to read and $184(22.2 \%)$ of the respondent's parents were educated secondary and above. Six hundred ninety $(83.4 \%)$ of the respondent's father and $552(66.7 \%)$ of the respondent's mothers were farmer. (Table2)

Table 2. Socio demographic characteristics of respondents' family among west Shoa zone, Oromia region high School students, May, 2013.

\begin{tabular}{lll}
\hline Variables & Frequency & Percent \\
\hline Level of parent education & 322 & \\
Illiterate & 138 & 38.9 \\
Read & 184 & 16.7 \\
primary & 184 & 22.2 \\
Secondary and above & & 22.2 \\
Student's father occupation & 690 & \\
Farmer & 138 & 83.4 \\
Civil servant & & 16.6 \\
Student's mothers occupation & 552 & \\
Farmer & 184 & 66.7 \\
House wife & 92 & 22.2 \\
Others & & 11.1 \\
\hline
\end{tabular}

One hundred thirty eight $(16.7 \%)$ of the respondents were reported chat chewing, 552(66.7\%) of the respondents were reported alcohol consumption and $322(38.9 \%)$ of the students were attended video.

Table 3. History of substance intakes of respondents among west Shoa zone, Oromia region high School students, May, 2013.

\begin{tabular}{|c|c|c|}
\hline Variables & Frequency & Percentage \\
\hline \multicolumn{3}{|c|}{ Chat chewing } \\
\hline Yes & 138 & 16.7 \\
\hline No & 690 & 83.3 \\
\hline \multicolumn{3}{|c|}{ Drinking alcohol } \\
\hline Yes & 552 & 66.7 \\
\hline No & 276 & 33.3 \\
\hline \multicolumn{3}{|c|}{ Attending video } \\
\hline Yes & 322 & 38.9 \\
\hline No & 506 & 61.1 \\
\hline
\end{tabular}

The majority of the respondents, $552(66.7 \%)$ had ever sexual partner. Among those who had sexual partner, 506 of the students had ever sexual practice. Of the respondents who had sexual practice, $186(36.8 \%), 230(45.4 \%)$ of the respondents were less than 15 years and between 15 and 19 years of age at their first sexual exposure respectively. Three hundred twenty two (58.3\%) of the respondents had one sexual partner, whereas the rest of participants had two or more sexual partners. 
Table 4. Sexual practices of respondents among west Shoa zone, Oromia region high School students, May, 2013.

\begin{tabular}{|c|c|c|}
\hline Variables & Frequency & Percentage \\
\hline \multicolumn{3}{|c|}{ Have ever sexual partner } \\
\hline Yes & 552 & 66.7 \\
\hline No & 276 & 33.3 \\
\hline \multicolumn{3}{|c|}{ Have ever sexual intercourse } \\
\hline Yes & 506 & 61.1 \\
\hline No & 322 & 38.9 \\
\hline \multicolumn{3}{|c|}{ Age at $1^{\text {st }}$ sexual intercourse } \\
\hline$<15$ & 92 & 18.2 \\
\hline $15-19$ & 230 & 45.4 \\
\hline $20-24$ & 184 & 36.4 \\
\hline \multicolumn{3}{|c|}{ Relationship with their $1^{\text {st }}$ sexual partner } \\
\hline An acquaintance & 138 & 25 \\
\hline Fiance & 92 & 16.7 \\
\hline Friend & 276 & 50.0 \\
\hline Others & 46 & 8.3 \\
\hline \multicolumn{3}{|c|}{ Currently having sexual partner } \\
\hline Yes & 552 & 66.7 \\
\hline No & 276 & 33.3 \\
\hline \multicolumn{3}{|c|}{ Reason for engaging in sexual partnership currently } \\
\hline Fail in love & 230 & 41.7 \\
\hline To get money & 46 & 8.3 \\
\hline Peer pressure & 184 & 33.3 \\
\hline Had desire & 92 & 16.7 \\
\hline \multicolumn{3}{|c|}{ Number of sexual partners } \\
\hline One & 322 & 58.3 \\
\hline Two & 138 & 25 \\
\hline Three-four & 92 & 16.7 \\
\hline \multicolumn{3}{|c|}{ Have Sexual intercourse in the last 12 months } \\
\hline Yes & 506 & 91.7 \\
\hline No & 46 & 8.3 \\
\hline \multicolumn{3}{|l|}{ Used contraceptive } \\
\hline Yes & 460 & 90.9 \\
\hline No & 46 & 9.1 \\
\hline
\end{tabular}

Among those who were started to practice sexual intercourse $276(33.3 \%)$ were males and $230(27.8 \%)$ were females. Two hundred five (24.8\%), 176(21.3\%), 54 (6.5\%), and $71(8.6 \%)$ were started sexual intercourse at grade 9 , grade 10 , grade 11 and grade 12 respectively. (Fig $1 \& 2$ )

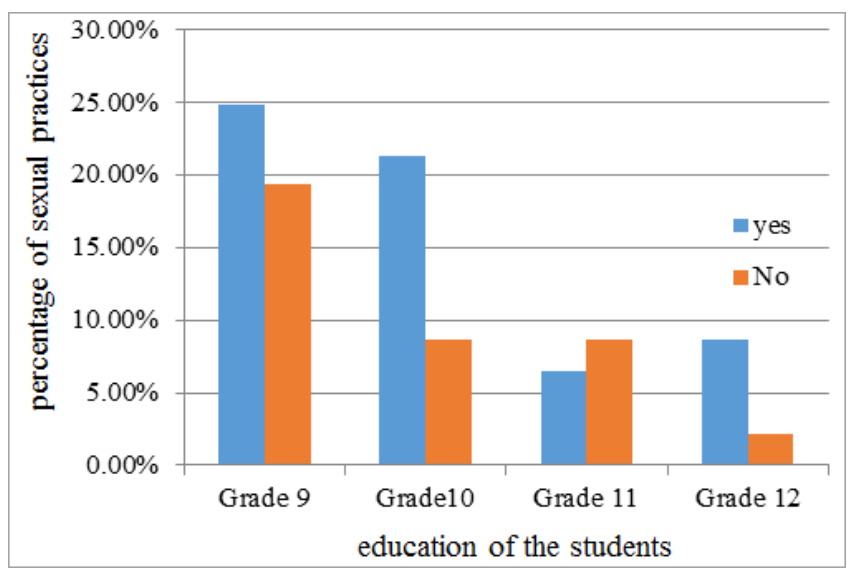

Fig. 1. The distribution of the participants sexual practice by the educational level among west Shoa zone, Oromia region high School students, May, 2013.

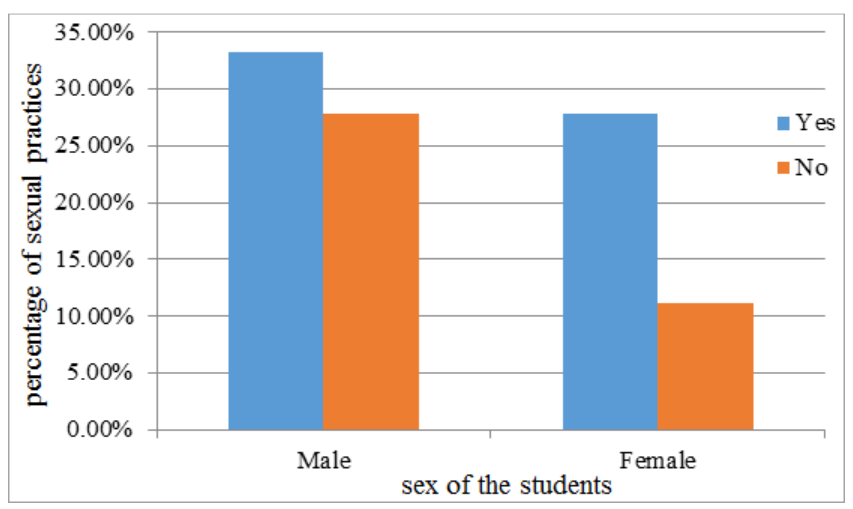

Fig. 2. The distribution of the participants sexual practice by sex among west Shoa zone, Oromia region high School students, May, 2013.

\subsection{Factors Associated with Premarital Practice}

$\mathrm{Bi}$-viriate and Multi-viriate logistic regression was used to identify the factors contributing to premarital sexual practice in the lifetime of the adolescents. Coefficients were expressed as crude and adjusted OR relative to the referent category and a number of risk factors were emerged as a significant predictors of premarital sexual practices.

Among the socio-demographic variables, sex of the respondents(female) $(\mathrm{COR}=0.48 ; 95 \% \mathrm{CI}=0.36-0.65)$, the respondent's parent education who were illiterate and able to read $(\mathrm{COR}=2.25 ; 95 \% \mathrm{CI}=1.25-3.36$ and $\mathrm{COR}=6.0 ; 95 \%$ $\mathrm{CI}=3.69-9.76$ respectively) and participants who have no pocket money $(\mathrm{COR}=0.14 ; 95 \% \mathrm{CI}=0.09-0.20)$ as well as from the behavioral variables, students who did not talk with parent about sexual issues $(\mathrm{COR}=3.43 ; 95 \% \mathrm{CI}=2.39-4.92)$, students who drinking alcohol $(\mathrm{COR}=5.0 ; 95 \% \mathrm{CI}=3.50$ $7.15)$, participants who attending video/ movies $(\mathrm{COR}=3.56$; $95 \% \mathrm{CI}=2.65-4.77)$, students who have no information about sexual issues $(\mathrm{COR}=4.0 ; 95 \% \mathrm{CI}=2.71-5.89)$ were significantly associated with pre-marital sexual practice of the students. Almost most of the above variables remained statistically significantly associated during multivariate regression. Females were $52 \%$ less likely engaged in premarital sexual practices when compared to male students. Students who have parent able to read but not formally educated were 2 times more likely practice premarital sexual behavior when compared with students who have parent's educated secondary school and above. Participants who did not discuss with their parent about sexual issues were 4.31 times more likely exposed to premarital sexual practice when compared to those who discus with their parent. Participants who have no pocket money were $90 \%$ less likely engaged in premarital sexual practice when compared to participants who have pocket money. Students who drink alcohol and attend video/movies were 2.63 and 4.03 times more likely involved in premarital sexual practice when compared to students who did not drink alcohol and did not attend video/movies respectively. 
Table 5. Factors associated with sexual practice of respondents among west Shoa zone, Oromia region high School students, May, 2013.

\begin{tabular}{|c|c|c|c|c|}
\hline \multirow{2}{*}{ Variables } & \multicolumn{2}{|c|}{ Have ever sexual intercourse } & \multicolumn{2}{|l|}{ OR $(95 \%) \mathrm{CI}$} \\
\hline & Yes & No & COR & AOR \\
\hline \multicolumn{5}{|l|}{ Sex } \\
\hline Male & $276(33.3)$ & $230(27.8)$ & 1 & 1 \\
\hline \multicolumn{5}{|l|}{ Grade } \\
\hline $9^{\text {th }}$ & $205(24.8)$ & 161(19.4) & 1 & 1 \\
\hline $10^{\text {th }}$ & $176(21.3)$ & $72(8.7)$ & $0.52(0.37,0.73)^{*}$ & $0.35(0.24,0.51)^{*}$ \\
\hline $12^{\text {th }}$ & $71(8.6)$ & $17(2.1)$ & $0.31(0.17,0.54)^{*}$ & $0.43(0.24,0.79)^{*}$ \\
\hline \multicolumn{5}{|l|}{ Parent education } \\
\hline Illiterate & $184(22.2)$ & $138(16.7)$ & $2.25(1.25,3.36)^{*}$ & $1.04(0.60,1.78)$ \\
\hline Read & $46(5.6)$ & $92(11.1)$ & $6(3.69,9.76)^{*}$ & $2(1.08,3.72)^{*}$ \\
\hline primary & $138(16.7)$ & $46(5.6)$ & $1(0.62,1.60)$ & $1.88(0.86,4.11)$ \\
\hline Secondary and above & $138(16.7)$ & $46(5.6)$ & 1 & 1 \\
\hline \multicolumn{5}{|c|}{ Talk with parent about sexual issues } \\
\hline Yes & $184(22.2)$ & $46(5.6)$ & 1 & 1 \\
\hline \multicolumn{5}{|l|}{ Having pocket money } \\
\hline Yes & $230(27.8)$ & $276(33.3)$ & 1 & 1 \\
\hline No & $276(33.3)$ & $46(5.6)$ & $0.14(0.09,0.20)^{*}$ & $0.10(0.07,0.16)^{*}$ \\
\hline \multicolumn{5}{|l|}{ Drinking alcohol } \\
\hline Yes & $276(33.3)$ & $276(33.3)$ & $5(3.50,7.15)^{*}$ & $2.63(1.75,3.95)^{*}$ \\
\hline No & $46(5.6)$ & $230((27.8)$ & 1 & 1 \\
\hline \multicolumn{5}{|l|}{ Attend video, movies } \\
\hline Yes & $138(16.7)$ & $184(22.2)$ & $3.56(2.65,4.77)^{*}$ & $4.03(2.56,6.34)^{*}$ \\
\hline No & $368(44.4)$ & $138(16.7)$ & 1 & 1 \\
\hline \multicolumn{5}{|c|}{ Have information about sexual issues } \\
\hline Yes & $460(55.6)$ & $230(27.8)$ & 1 & 1 \\
\hline No & $46(5.6)$ & $92(11.1)$ & $4.0(2.71,5.89)^{*}$ & $1.29(0.74,2.23)$ \\
\hline
\end{tabular}

N.B. * indicate P-value less than 0.05

\section{Findings of Qualitative Study}

A total of 24 participants were invited in 3 focus group discussions. The results of the focus group discussion were summarized as follows;

\section{Students' Premarital Sexual Practice}

The discussants mentioned that premarital sexual practice is widely been practiced in the area. The discussants estimated as high as $80 \%$ of the adolescents are practicing sexual intercourse before marriage. They further explained that the practice is usually unprotected and so, many girls are getting pregnant and commit suicides. One of the discussants said 'I think, now a day, adolescents' premarital sexual intercourse is becoming uniformly a fashion and practice throughout the country."

\section{Risk Factors for Pre-Marital Sexual Practice}

Almost all discussants agreed that most of the adolescents start sexual intercourse at the age of 15 years, at this age, their bodies mature and their biological needs to sexual practice increases.

A 19 years old discussant said:

"Once the girl's breasts start to grow and become visible, it is a time for males to ask that girl for sexual relationship. Then communication begins to mislead the girl by enticing her, because girls are misleaded by males' sweet words that unexpectedly lead to engage in sexual practice.

Substance intake was the risk factor for initiation of sexual intercourse like khat chewing and alcohol drinking. The discussants were mentioned that when boys drink, they lose their control over their sexual need and get forced to engage sexual practice.

Most of the discussants said, "Adolescents watch bad films (such as pornographic films), dramas and music about sex, and then they get sexual arousal and get forced to do it.

One of the most contributing factors stressed by almost all discussants was girls' bad clothing style such as tight trousers, short skirts and short "T"- shirts that expose their buttocks, umbilicus and breasts. These clothing styles were even condemned by the girl discussants themselves.

A 17 years old male discussant said: 'As males' sweet words mislead girls, girls' clothing styles mislead boys. Therefore girls should wear a normal cloth that doesn't expose their body."

The other important point mentioned was that there is no open discussion on sexual issues among adolescents and their families. Most of the discussants agreed that discussing about sexual issues in the family is difficult, because, the adolescents fear not to be labeled by their families as "bad boy or bad girl."

One discussant said: "It was good if there is an open 
discussion in the family, because the families teach their children from their experiences based on reality, as they have seen everything. But since we fear them we don't want to hear them, rather we prefer our peers and we openly discuss with our peers."

A 16 year old female discussant said: "I fear to discuss sexual issues with my father, but I discuss it with my mother as my relation with my mother is so intimate that she tells me everything openly. She tells me her experience without any reservations."

\section{Discussion}

This study has tried to assess the premarital sexual practice and factors influencing the premarital sexual practice of high school students in west Shoa zone, Oromia region. In this study the majority of the students, 506(61.1\%) were practiced sexual intercourse with one or more sexual partner(s). The finding of this study was higher than the findings of different studies done previously, a study done in North West Ethiopia which was $52.8 \%$ and another study done in Gondor University medical college students which was $58 \%$ of the students were practiced premarital sexual intercourse $(11,16)$. The reason might be the variation of the time studies conducted; the participants of this study easily access to various sexual related videos and movies that push the students to engage in early sexual practice. This also supported by the finding of focus group discussion.

Regarding the age of the participants sexual initiation, $92(18.2 \%)$ of the students were started sexual intercourse less than the age of 15 years old and $230(45.4 \%)$ started between the age of 15-19 years of age with the mean age of first sexual initiation was 17 years of age. The present study finding was almost consistence with the age interval of sexual intercourse initiation with other studies done in Ethiopia; the finding of Jimma university study's which was from 10-24 years of age (15). But as the findings of both qualitative and focus group discussion indicated early premarital sexual intercourse was commonly practiced in the study area.

Regarding the distribution of sexual practices of the participants $276(33.3 \%)$ were males and 230 (27.8\%) were females. This indicates that males were more practiced premarital sexual intercourse than females. The present study finding was higher than the findings of various studies done previously; the national HIV AIDS behavioral surveillance survey finding was lower than this finding which was $19 \%$ of males and $13 \%$ of females of the in-school youth had ever had sex. (22).

In this study the majority of the participants (72.2\%) were not discussed with their parent about sexual related issues. The present study finding was higher than the findings of study done in Ziway high school students which was $54 \%$ of the students reported discussing about physical and psychological changes during adolescent is culturally shameful. One reason for this variation might be the different in the study area, the current study include the students from the rural area where there is less open discussion between the parents and children. This finding was also supported by the finding of focus group discussion that most of the discussants agreed that there is no open discussion within the family about sexual related issues.

This study also tried to identify the factors associated with the students' premarital sexual practice. Among the sociodemographic variables sex of students, participants' parent educational status, pocket money and student's grade level, from the behavioral factors discussion with parent about sexual related issues, drinking alcohol, attending video and having information about sexual related issues were the factors which were statistically associated with premarital sexual practices of the students. This finding was strongly supported by the finding of focus group discussion. The group discussants were reported when boys drink alcohol, they lose their control over their sexual need and get forced to engage sexual practice. Most of the discussants also agreed adolescents who watch pornographic films, drams and music about sex and then forced to practice it.

\section{Conclusion}

In this study the premarital sexual practice and associated factors were assessed. Based on the finding of both qualitative and quantitative studies premarital and early sexual practice was commonly practiced by most school adolescents. Five hundred six $(61.1 \%)$ of the participants were practiced premarital sexual intercourse with one or more sexual partners. Among those $92(18.2 \%)$ and 230 $(45.4 \%)$ were started sexual intercourse at the age of less than 15 years and between 15-19 years of age respectively.

The majority of the participants $(72.2 \%)$ were not discussed with their parent about sexual related issues.

Among the socio-demographic variables, sex of the respondents (female), the respondent's parent educational status and participants who have no pocket money as well as from the behavioral variables, students who did not talk with parent about sexual issues, students who drinking alcohol, participants who attending video/ movies, students who have no information about sexual issues were significantly associated with pre-marital sexual practice of the students. Among the socio-demographic variables, sex of the respondents (female), the respondent's parent educational status and participants who have no pocket money as well as from the behavioral variables, students who did not talk with parent about sexual issues, students who drinking alcohol, participants who attending video/ movies, students who have no information about sexual issues were significantly associated with pre-marital sexual practice of the students.

\section{Recommendation}

Based on the finding of the study the following recommendation were developed.

- To minimize the prevalence of premarital sexual practice and early sexual practice initiation Ambo 
university as part of community service with other stakeholders should work in the provision of adolescent reproductive health service for school adolescents.

- Health and education offices at different level should work together in order of promoting open discussion about sexual related issues and provide adequate and updated reproductive related information through school health education, establishing reproductive health club in the school.

- The community and the family also should discussed with school adolescents about sexual related issues.

- The students also avoid unhealthy behaviors like taking substances (drinking alcohol), watching videos that push them to engaged to sexual practice.

\section{References}

[1] EPHA, ARH. Task force Adolescent Reproductive Health Global and National initiatives and Lesson Learned, Aug.2003.

[2] HIV/AIDS Prevention and Control Office (HAPCO). Behavioral Surveillance Survey (BSS) in Ethiopia.-2000

[3] PAV Govindasamy, Youth Reproductive Health in Ethiopia, Addis Ababa,Nov.2002.

[4] International strategies that work for youth, summary of focus on young adults, end of program report, 2002.

[5] International Family planning prospectuses, March 2003, volume 29, No 1 .

[6] Kassaye Z. Sexual Experiences and their correlated among Jimma University students, Jimma University, 2002.
[7] Family Health International (FHI). US, Agency for International Development (UNAIDS): YOUTH Net partners in Reproductive Health and HIV prevention. April 2004.

[8] WHO/ UNDP /World Bank .Special Program of Research Development and Research Training in Human Reproduction. News58.htm.

[9] Eshetu ,F.,Zakus,D. and Kebede, The attitude of students, parents and teachers towards the promotion and provision of condoms for adolescents in Addis Ababa. Ethiopian .J. Health Dev.1997,11:7-11.

[10] Taffa N, Haimanot R, Desalegn S, Tesfaye A, Mohamed K. Do parents and young people communicate on sexual matters? The situation of family life education (FLE) in rural town in Ethiopia.Ethiop.J.HealthDev, Dec 1999; 13(3):207)

[11] MaartjeVersnel, YemaneB,Johannes.F, wend F.Sexuality and contraception among never married high school students in Butagira . Ethiop Med J 2002; 40(1):46)

[12] Assefa Seme, Dessalegn Wirtu,premarital sexual practice among school adolescent in Nekemt town, east wolega, Ethiop. J.Health dev. 2008;22(2):167-173.

[13] Habtamu M, Diresegn M, Hailu F, Assessment of time of sexual initiation and its associated factors among students in Northwest Ethiopia, Science Journal of Public Health; 2015,3(1): 10-18

[14] Adisu S., Abdulbasit M, Prevalence of premarital sex and associated factors among out of-school youths (aged 15-24) in Yabello town, Southern Ethiopia: A community based crosssectional study, The Pharma Innovation Journal; 2014, 3(10): $10-15$. 